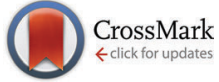

Cite this: J. Mater. Chem. C, 2016, 4, 2312

Received 1st February 2016,

Accepted 25th February 2016

DOI: $10.1039 / c 6 t c 00489 j$

www.rsc.org/MaterialsC

\section{Chemical vapour deposition of rhenium disulfide and rhenium-doped molybdenum disulfide thin films using single-source precursors $\dagger$}

\author{
Naktal Al-Dulaimi, ${ }^{a}$ David J. Lewis, ${ }^{\text {ab }}$ Xiang Li Zhong, ${ }^{b}$ M. Azad Malik ${ }^{b}$ and \\ Paul O'Brien*ab
}

\begin{abstract}
Polycrystalline thin films of rhenium disulfide $\left(\operatorname{ReS}_{2}\right)$ and the alloys $M 0_{1-x} \operatorname{Re}_{x} S_{2}(0 \leq x \leq 0.06)$ have been deposited by aerosol-assisted chemical vapour deposition (AA-CVD) using $\left[\operatorname{Re}\left(\mu-S^{i} \operatorname{Pr}\right)_{3}\left(S^{i} \operatorname{Pr}\right)_{6}\right]$ (1) and $\left[\mathrm{Mo}\left(\mathrm{S}_{2} \mathrm{CNEt}_{2}\right)_{4}\right]$ (2) in different molar ratios at $475{ }^{\circ} \mathrm{C}$. The deposited films were characterised by $\mathrm{p}-\mathrm{XRD}$, SEM, and ICP-OE, Raman, and EDX spectroscopies. The $p$-XRD patterns of the films deposited from (1) correspond to $\operatorname{ReS}_{2}(x=1)$ and those deposited from (2) matched to $\operatorname{MoS}_{2}(x=0)$. Re-doping of up to $6 \%$ was achieved in $\mathrm{MoS}_{2}$ thin films by using different concentrations of precursor (1), the morphology of the doped films changed from lamellar for pure $\mathrm{MoS}_{2}$ to clusters at $6 \mathrm{~mol} \%$ alloying with rhenium. The films are promising candidates as models for the incorporation of technetium into transition metal dichalcogenides as a means of immobilisation in nuclear waste processing. Exfoliation of these films is also a potential route towards modification of the optoelectronic properties of 2D molybdenite.
\end{abstract}

\section{Introduction}

Two-dimensional transition metal dichalcogenides (TMDCs) which have the general formula $\mathrm{MX}_{2}$, including molybdenum disulfide $\left(\mathrm{MoS}_{2}\right)$, tungsten disulfide $\left(\mathrm{WS}_{2}\right)$, and tungsten diselenide $\left(\mathrm{WSe}_{2}\right)$ have attracted interest because of their optoelectronic properties in monolayer form ${ }^{1-3}$ with useful carrier mobilities and mechanical flexibility. ${ }^{4-9} \mathrm{MoS}_{2}$, in particular, has attracted considerable attention because of its potential applications in hydrogen storage, solid lubricants, capacitors, and electrochemical devices. ${ }^{10-14} \mathrm{MoS}_{2}$ can also be used as a catalyst (e.g. in hydrogen evolution reactions) due to its high-energy crystal edges. ${ }^{15}$ The structure of bulk $\mathrm{MoS}_{2}$ is akin to that of graphite in terms of a repeating layer structure, ${ }^{16}$ held together by non-covalent interactions. $2 \mathrm{H}-\mathrm{MoS}_{2}$ bulk shows a change from an indirect bandgap to a direct bandgap as the $1 \mathrm{H}-\mathrm{MoS}_{2}$ monolayer form is approached, ${ }^{15}$ as per $\mathrm{MoSe}_{2}, \mathrm{WSe}_{2}$, and $\mathrm{WS}_{2} \cdot{ }^{17,18} \mathrm{MoS}_{2}$ thin films have been synthesised by aerosol assisted chemical vapour deposition (AA-CVD) using metal dithiocarbamate-based precursors. ${ }^{19}$ Thin films of $\mathrm{MoS}_{2}$ doped with Re have been previously synthesised by using spray pyrolysis. ${ }^{20}$ We and others

\footnotetext{
${ }^{a}$ School of Chemistry, The University of Manchester, Oxford Road M13 9PL, UK. E-mail: Paul.O'Brien@manchester.ac.uk; Tel: +44 (0)161 2754652

${ }^{b}$ School of Materials, The University of Manchester, Oxford Road, M13 9PL, UK $\dagger$ Electronic supplementary information (ESI) available: Characterization of $\mathrm{MoS}_{2}$ thin films produced by AA-CVD at $475{ }^{\circ} \mathrm{C}$, simulated p-XRD pattern of $\mathrm{ReS}_{2}$ and TEM of Re-doped $\mathrm{MoS}_{2}$. See DOI: 10.1039/c6tc00489j
}

have recently developed a general approach to doping $\mathrm{MoS}_{2}$ with transition metal cations such as chromium based on AA-CVD. ${ }^{21,22}$

Rhenium disulfide $\left(\mathrm{ReS}_{2}\right)$ has a direct bandgap which remains as such in the monolayer form unlike most other TMDCs. Few, if any, changes are observed in the Raman spectrum of monolayer $\mathrm{ReS}_{2}$ compared to bulk and few-layer variants. ${ }^{23}$ Transition metal doped $\mathrm{ReS}_{2}$ has been reported. ${ }^{24}$ Single crystals of Mo-doped $\mathrm{ReSe}_{2}$ have been synthesised by chemical vapour transport method with bromine as a transport agent. ${ }^{25}$ The growth of $\mathrm{ReS}_{2}$ monolayers has been achieved using CVD at $450{ }^{\circ} \mathrm{C}$, the as-deposited $\mathrm{ReS}_{2}$ is an n-type semiconductor. ${ }^{26}$ Colloidal $\mathrm{ReS}_{2}$ nanoparticles have also been prepared. ${ }^{27}$ Two-dimensional nanosheets of $\mathrm{ReS}_{2}$ have been synthesised by lithium intercalation, and have unique photocatalytic properties which can potentially be superior to other twodimensional materials. ${ }^{28}$ Large area deposition of $\mathrm{ReS}_{2}$ sheets with good crystallinity has been achieved using simple CVD, from $\mathrm{ReO}_{3}$ treated with elemental sulfur vapour at $500{ }^{\circ} \mathrm{C} .{ }^{29}$

Rhenium-doped $\mathrm{MoS}_{2}$ can potentially be used as a model for immobilization of radioactive technetium-99 $\left({ }^{99} \mathrm{Tc}\right) .{ }^{30}$ Technetium99 is very mobile in water hence there is concern about its release into the environment. In 2008 the production of ${ }^{99} \mathrm{Tc}$ was close to 290 metric tonnes worldwide. ${ }^{31}$ Technetium-99 is produced from uranium fission, and is present in nature at a very low level. ${ }^{32}{ }^{99} \mathrm{Tc}$ has a long half-life ( $c a .2 \times 10^{5}$ years), and it forms about $6 \%$ of the fission product from uranium. ${ }^{33,34}$ The relatively short-lived isotope ${ }^{99} \mathrm{~m}$ Tc is a widely used radionuclide in nuclear medicine. ${ }^{35}$

The ionic radii of $\mathrm{Tc}(\mathrm{Iv}), \operatorname{Re}(\mathrm{Iv})$ and $\mathrm{Mo}(\mathrm{Iv})$ are $0.65,0.63$ and $0.65 \AA$ respectively, whilst the Shannon-Prewitt crystal radii of 
Tc(Iv), Re(Iv) and Mo(Iv) are also similar, 0.79, 0.77 and $0.79 \AA$ respectively. ${ }^{36}$ The Gibbs free energy change associated with the formation of the $\mathrm{M}(\mathrm{Iv})$ oxidation state from elemental rhenium and technetium are $\Delta G=1.3 F$ and $1.1 F \mathrm{~kJ} \mathrm{~mol}^{-1}$ respectively, where $F$ is the Faraday constant. ${ }^{37}$ Hence from these data it may be surmised that isovalent substitution of Re into $\mathrm{MoS}_{2}$ may be performed without significant induced strain in the lattice and minimal free energy penalty from disruption of the host lattice and that rhenium(Iv) is a good model for technetium(Iv). Entrainment of Re into host structures such as iron phosphate glasses is also known ${ }^{38}$

In this paper we report the deposition of $\mathrm{Mo}_{1-x} \mathrm{Re}_{x} \mathrm{~S}_{2}(0 \leq x \leq$ 0.06) alloyed thin films using AA-CVD from Mo and Re single source precursors. Molybdenite exists usually as the $2 \mathrm{H}$ stacked (ABA) polytype $\left(\mathrm{P}_{3} \mathrm{mmc}\right) .^{39,40}$ Rhenium disulfide has a different layered structure that is classified in the $P \overline{1}$ space group, ${ }^{41}$ of much lower symmetry than most transition metal dichalcogenides which seems to be driven by the participation of each $d^{3}$-Re ion bonding to three others in the same layer which results in the formation of $\mathrm{Re}_{4}$ parallelograms, with vertices linked in a linear fashion throughout the sheet. The Re-based parallelograms dictate the relative displacements of the sulfur atoms in the hexagonal close packed arrays, and due to this, the sulfur atoms in the layer are rippled on the sheet surface, in contrast to $\mathrm{MoS}_{2}$, where the sulfur layers appear smooth. At low levels of rhenium incorporation we find that the parent molybdenite structure holds due to the aforementioned similarities in crystal radii and the thermodynamic similarities in their +4 oxidation state. Significantly, this makes Re-doped $\mathrm{MoS}_{2}$ a potentially useful model system for understanding the thermodynamic stability of ${ }^{99} \mathrm{Tc}$ in a host molybdenum disulfide lattice which will be of particular interest in nuclear chemistry for storage capability-building using inert materials that do not leach radioactive material. This is the first example of single source precursors being used to produce such materials.

\section{Experimental section}

All reactions were carried out under dry nitrogen atmosphere using standard Schlenk techniques. Solvents were purchased from Sigma-Aldrich or Fisher and used without further purification. Reagents were purchased from Sigma-Aldrich.

\section{Instrumentation}

Elemental analysis was performed by the University of Manchester micro-analytical laboratory. A Seiko SSC/S200 model was used for TGA measurements with a heating rate of $10{ }^{\circ} \mathrm{C} \mathrm{min}{ }^{-1}$ under nitrogen. Scanning electron microscopy (SEM) was performed in secondary electron mode with a Zeiss Ultra55 microscope with an accelerating voltage of $10 \mathrm{kV}$. Energy-dispersive X-ray (EDX) spectroscopy was performed on the same system at an accelerating voltage of $30 \mathrm{kV}$ using an Oxford Instruments INCA pentaFETx3 detector. Transmission electron microscopy (TEM) was performed on a FEI Tecnai G2 operating at $200 \mathrm{kV}$. Nuclear magnetic resonance (NMR) spectra were recorded using a $400 \mathrm{MHz}$ Bruker spectrometer. A Bruker D8 AXE diffractometer was used to record p-XRD patterns, equipped with a Cu- $\mathrm{K}_{\alpha}$ source $(1.5406 \AA)$. Thin films were scanned between 10 and $80^{\circ}$ with step size $0.02^{\circ}$ and a dwell time of $3 \mathrm{~s}$.

\section{Synthesis of rhenium nonachloride $\left(\mathrm{Re}_{3} \mathrm{Cl}_{9}\right)$}

The apparatus was dried by heat gun in a stream of dry nitrogen, and then was moved with the stopcock closed into a glove bag. Rhenium pentachloride $\left(\mathrm{ReCl}_{5}, 2.35 \mathrm{~g}\right)$ was added into the tube and moved from the glove bag and clamped, with a moderate stream of $\mathrm{N}_{2}$. The tube was heated in a slow Bunsen burner flame, after that the $\mathrm{ReCl}_{5}$ started to melt and the vapour was under reflux. Brown fumes were observed to be liberated. Heating was stopped during the reaction at regular intervals to harvest the crystals which were formed on the wall of tube. This process was repeated until no more brown fumes were liberated and only solid remained. ${ }^{42}$ The apparatus was allowed to cool, and the tube sealed off and moved to a nitrogen filled glove bag to transfer the product, a black-red solid, into an ampoule. Yield: $72 \%$. Anal. calc. for $\mathrm{Re}_{3} \mathrm{Cl}_{9}(\%)$ : $\mathrm{Re}, 63.65 ; \mathrm{Cl}$, 36.65. Found (\%): Re, 61.63; Cl, 36.57 .

\section{Synthesis of $\left(\mathrm{Re}_{3} \mathrm{Cl}_{9}(\mathrm{THF})_{3}\right)$}

$\mathrm{Re}_{3} \mathrm{Cl}_{9}(\mathrm{THF})_{3}$ was prepared as previously reported, ${ }^{43} \mathrm{Re}_{3} \mathrm{Cl}_{9}$ $(2.3 \mathrm{~g}, 2.6 \mathrm{mmol})$ was placed into a thimble in the Soxhlet, then $\mathrm{Re}_{3} \mathrm{Cl}_{9}$ was extracted from a Soxhlet thimble by refluxing with THF (40 mL) under nitrogen over $48 \mathrm{~h}$ or more until the solvent passing through the thimble became colorless. The THF solvent was evaporated and then dark purple solid was collected and washed with diethyl ether $(2 \times 20 \mathrm{~mL})$. Traces of solvent were removed in vacuo to furnish the title product. Yield: 58\%. IR $\left(\nu_{\max } / \mathrm{cm}^{-1}\right): 2956(\mathrm{w}) 1481(\mathrm{w}), 1442(\mathrm{w}), 1336(\mathrm{w})$, 1042 (w), 1014 (m), 917 (w), 839 (s), 686 (w).

\section{Synthesis of rhenium iso-propylthiolate $\operatorname{Re}_{3}\left(\mu-\operatorname{SPr}^{i}\right)_{3}\left(\operatorname{SPr}^{i}\right)_{6},(1)$}

This compound was prepared using the method of Cohen and co-workers. ${ }^{44}$ Briefly, $\mathrm{Re}_{3} \mathrm{Cl}_{9}(\mathrm{THF})_{3}(1.7 \mathrm{~g}, 1.5 \mathrm{mmol})$ was dissolved in of THF $(140 \mathrm{~mL})$. Sodium isopropylthiolate $(1.7 \mathrm{~g}$, $17.8 \mathrm{mmol}$ ) was added to the red solution of $\mathrm{Re}_{3} \mathrm{Cl}_{9}(\mathrm{THF})_{3}$. This mixture was refluxed for $48 \mathrm{~h}$ after which the THF was removed under reduced pressure. The resulting solid was then extracted with hexane $(5 \times 20 \mathrm{~mL})$; the combined organic phase was filtered through Celite, the solvent was removed by reduced pressure then dried by vacuum oven overnight. Yield: $55 \%$. Anal. calc. for $\mathrm{Re}_{3} \mathrm{~S}_{9} \mathrm{C}_{27} \mathrm{H}_{63}$ (\%) C, 26.28; H, 5.14; found (\%) C, 25.82; H, 5.77. ${ }^{1} \mathrm{H} \mathrm{NMR}\left(\mathrm{CDCl}_{3}, 400 \mathrm{MHz}\right.$ ) $\delta / \mathrm{ppm}: 1.18(\mathrm{~d}, J=$ $6.81 \mathrm{~Hz}, 3 \mathrm{H}, \mathrm{SCHMe}_{2}$ ), 1.21 (d, $\left.J=6.81 \mathrm{~Hz}, 3 \mathrm{H}, \mathrm{SCHMe}_{2}\right) 1.23$ (d, $\left.J=6.56 \mathrm{~Hz}, 3 \mathrm{H}, \mathrm{SCHMe} e_{2}\right) 1.27$ (d, $J=6.81 \mathrm{~Hz}, 3 \mathrm{H}, \mathrm{SCHMe}_{2}$ ), 1.37 (d, $J=6.81 \mathrm{~Hz}, 4 \mathrm{H}, \mathrm{SCHMe}_{2}$ ), 1.42 (d, $J=6.81 \mathrm{~Hz}, 4 \mathrm{H}$, $\left.\mathrm{SCHMe}_{2}\right), 1.58(\mathrm{~d}, J=6.81 \mathrm{~Hz}, 4 \mathrm{H}, \mathrm{SCHMe})_{2}, 1.70(\mathrm{~d}, J=4.29 \mathrm{~Hz}$, $3 \mathrm{H}, \mathrm{SCHMe}_{2}$ ), 1.71 (d, $J=4.29 \mathrm{~Hz}, 3 \mathrm{H}, \mathrm{SCHMe}$ ), 2.84-2.96 (septet, 1H, SCHMe 2 ), 3.40-3.53 (septet, 1H, SCHMe $e_{2}$ ), 3.55-3.67 (septet, 1H, SCHMe $e_{2}$ ), 3.99-4.12 (septet, 1H, SCHMe $e_{2}$ ), 4.19-4.32 (septet, 1H), 4.34-4.45 (septet, $1 \mathrm{H}, \mathrm{SCHMe}_{2}$ ), ${ }^{13} \mathrm{C} \mathrm{NMR}\left\{{ }^{1} \mathrm{H}\right\}$ $\left(\mathrm{CDCl}_{3}, 101 \mathrm{MHz}\right) \delta / \mathrm{ppm}: 22.61$ (s, 5C), 25.40 (s, 2C), 25.71 (s, 2C), 26.46 (s, 2C), 27.21 (s, 2C) 27.78 (s, 2C), 28.07 (s, 2C), $28.21(\mathrm{~d}, J=2.21 \mathrm{~Hz}, 5 \mathrm{C}), 28.50$ (s, 2C), 30.95 (s, 2C), 32.23 
(s, 1C), $37.32(\mathrm{~s}, 1 \mathrm{C}), 37.78(\mathrm{~s}, 1 \mathrm{C}), 41.46(\mathrm{~s}, 2 \mathrm{C}), 44.02(\mathrm{~d}, J=$ $7.37 \mathrm{~Hz}, 3 \mathrm{C}$ ), 44.05-44.28 (m, 2C), 46.89 (s, 1C).

Synthesis of tetrakis(diethylaminodithiocarbomato)molybdate(Iv) ([Mo( $\left.\left.\left.\mathrm{S}_{2} \mathrm{CNEt}_{2}\right)_{4}\right]\right),(2)$

A mixture of $\mathrm{Mo}(\mathrm{CO})_{6}(10 \mathrm{~g}, 37.8 \mathrm{mmol})$ and bis(diethylthiocarbamoyl)disulfide $(22.4 \mathrm{~g}, 75.6 \mathrm{mmol})$ was dissolved in degassed acetone $(400 \mathrm{~mL})$ and heated under reflux at a temperature range of $55-60{ }^{\circ} \mathrm{C}$ for $2 \mathrm{~h}$. The mixture was cooled to room temperature, which prompted violet crystals to appear which were filtered and washed with pentane and dried in vacuo, ${ }^{45}$ to yield the title product as dark microcrystals. Yield: $63 \%$. Anal calc. for $\mathrm{C}_{20} \mathrm{H}_{40} \mathrm{MoN}_{4} \mathrm{~S}_{8}$ (\%) C, 34.88; $\mathrm{H}, 5.86$; N, 8.14; S 37.16. Found (\%) C, 35.04; H, 6.05; N, 8.08; S 37.33. (mp 126-128 ${ }^{\circ} \mathrm{C}$ ). $\mathrm{MS}\left(\mathrm{ES}^{+}\right) \mathrm{m} / \mathrm{z}: 690.1[\mathrm{M}+\mathrm{H}]^{+}$.

\section{Aerosol-assisted chemical vapour deposition (AA-CVD)}

AA-CVD was used to deposit the rhenium or molybdenum sulfide thin films by employing $\left[\operatorname{Re}\left(\mu-\mathrm{S}^{\mathrm{i}} \mathrm{Pr}\right)_{3}\left(\mathrm{~S}^{\mathrm{i}} \mathrm{Pr}\right)_{6}\right](\mathbf{1})$ or $\left[\mathrm{Mo}\left(\mathrm{S}_{2} \mathrm{CNEt}_{2}\right)_{4}\right](\mathbf{2})$, at concentrations of $0.1 \mathrm{mmol}$ in $40 \mathrm{~mL}$ of $\mathrm{THF}$ at $475{ }^{\circ} \mathrm{C}$. In addition, $0.1 \mathrm{mmol}$ of total precursors $\left(\mathrm{mol}\left[\mathrm{Mo}\left(\mathrm{S}_{2} \mathrm{CNEt}_{2}\right)_{4}\right]\right.$ and mol $\left.\left[\operatorname{Re}\left(\mu-S^{i} \operatorname{Pr}\right)_{3}\left(S^{i} \operatorname{Pr}\right)_{6}\right]\right)$ were dissolved in $(40 \mathrm{~mL})$ THF to give solutions with differing composition (10, 20, 30, and $50 \mathrm{~mol} \%)$ to synthesis Re-doped $\mathrm{MoS}_{2}$. Argon was used as inert gas carrier with flow rate $180 \mathrm{sccm}$ in to the furnace where precursors decomposed and deposit on the glass substrates $(1 \times 2 \mathrm{~cm})$, which has been ultrasonically cleaned in isopropanol prior to use. The flow rate of argon was controlled using Platon flow gauge. Depositions typically lasted for $c a$. $\sim 3 \mathrm{~h}$.

\section{Results and discussion}

\section{Synthesis and characterisation of the rhenium and} molybdenum precursors

$\operatorname{Re}\left(\mu-\mathrm{S}^{\mathrm{i}} \mathrm{Pr}\right)_{3}\left(\mathrm{~S}^{\mathrm{i}} \mathrm{Pr}\right)_{6}(\mathbf{1})$ and $\mathrm{Mo}\left(\mathrm{S}_{2} \mathrm{CNEt}_{2}\right)_{4}$ (2) were synthesised by literature procedures. ${ }^{44,45}$ All characterisation data matched with that previously reported. Complex (1) was a dark red powder, whilst complex (2) appeared as dark purple crystals. Both precursors were freely soluble in THF. Thermogravimetric analysis (TGA) of complexes (1) and (2) was used to determine the thermal decomposition range for both complexes (Fig. 1). Precursor (1) decomposed in four steps in the temperature ranges of; 40-90 ${ }^{\circ} \mathrm{C}, 140-210{ }^{\circ} \mathrm{C}$, and $215-360{ }^{\circ} \mathrm{C}$, followed by a slower decomposition process in the temperature range $810-1000{ }^{\circ} \mathrm{C}$ and complete decomposition occurred after a $10 \mathrm{~min}$. hold at $1000{ }^{\circ} \mathrm{C}$. The remaining mass of residue (62\%) suggests the formation of a rhenium sulfide (calc. 61\%) (Fig. 1). Precursor (2), had a TGA profile consistent with that previously reported, ${ }^{22}$ showing four decomposition steps in the range $0-600{ }^{\circ} \mathrm{C}$ with a final residue $(29 \%)$ close to that of $\mathrm{MoS}_{2}$ (calc. 24\%).

\section{Deposition and characterization of $\operatorname{ReS}_{2}$ thin films}

Deposition of $\mathrm{ReS}_{2}$ films was performed using AA-CVD. The reactor temperature for deposition of $\mathrm{ReS}_{2}, \mathrm{MoS}_{2}$, and Re-doped $\mathrm{MoS}_{2}$ was chosen based on thermogravimetric analysis results

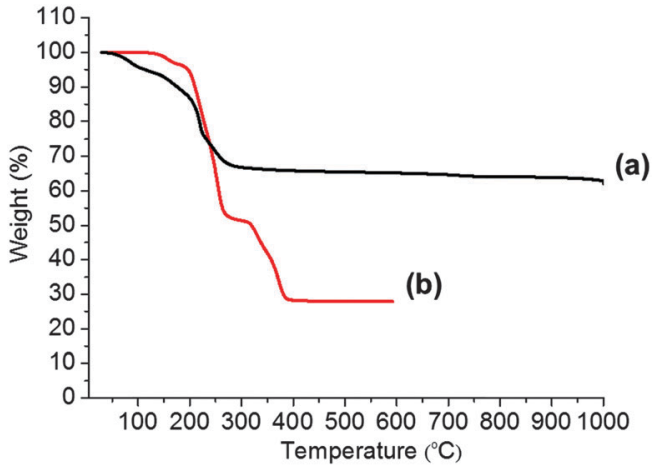

Fig. $1 \mathrm{TGA}$ of (a) $\operatorname{Re}\left(\mu-\mathrm{S}^{\mathrm{i}} \mathrm{Pr}\right)_{3}\left(\mathrm{~S}^{\mathrm{i}} \mathrm{Pr}\right)_{6}(\mathbf{1})$ and (b) $\left[\mathrm{Mo}\left(\mathrm{S}_{2} \mathrm{CNEt}_{2}\right)_{4}\right]$ (2) complexes.

(TGA, vide supra). Varying molar ratios of precursor (1) and (2) were used in a THF aerosol to achieve doped thin films which were deposited at $475^{\circ} \mathrm{C}$. The films were studied by inductively coupled plasma optical emission spectroscopy (ICP-OES), powder $\mathrm{X}$-ray diffraction (p-XRD), scanning electron microscopy (SEM) and Raman and energy dispersive X-ray (EDX) spectroscopies. The p-XRD pattern of rhenium disulfide thin films deposited at $475{ }^{\circ} \mathrm{C}$ (Fig. 2) revealed two major reflections at $2 \theta=14.37^{\circ}$, which is assigned to the (001) plane of $1 \mathrm{~T}-\mathrm{ReS}_{2}$, and at $2 \theta=27.89^{\circ}$ corresponding to the (111) plane. Thus the $\mathrm{ReS}_{2}$ produced by AACVD has an apparent preferred orientation in the (001) plane.

Raman spectroscopy of the films revealed vibrational modes that can be linked to $\mathrm{ReS}_{2}$ films. $\mathrm{E}_{\mathrm{g}}$ modes which we ascribe to in-plane vibrations of the $\mathrm{Re}$ atoms in $\mathrm{ReS}_{2}$, and $\mathrm{A}_{\mathrm{g}}$ modes corresponding to the out-of-plane vibrations of $\mathrm{Re}$ atoms (Fig. 3). The morphological features of thin films of rhenium sulfide were investigated by scanning electron microscopy (SEM), which revealed particles with teardrop morphology (Fig. 4a and b). Bright field transmission electron microscopy (TEM) reveals that this material is flake-like in appearance at the nanoscale (Fig. 4c-g),

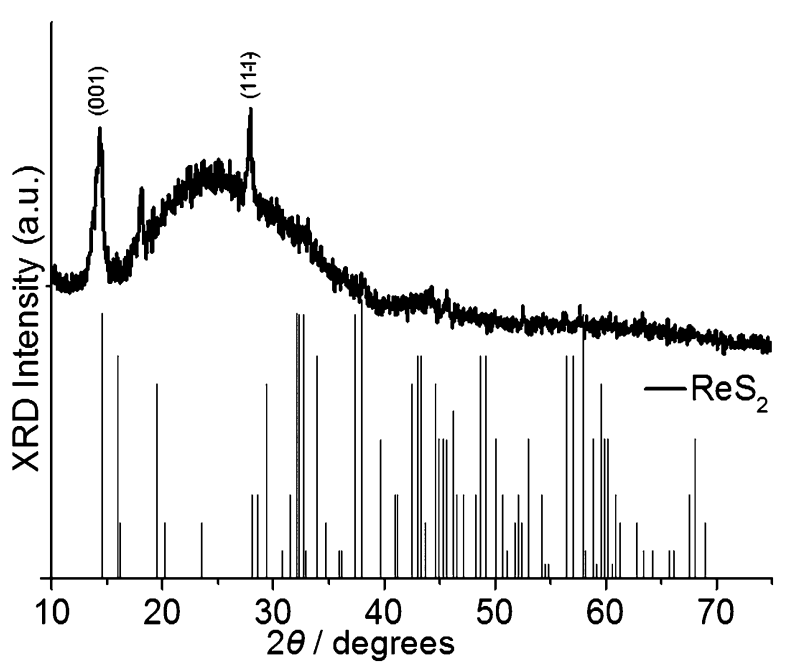

Fig. 2 Powder $\mathrm{X}$-ray diffraction pattern for rhenium disulfide $\left(\operatorname{Re}_{2}\right)$ deposited by AA-CVD using precursor (1) at $475^{\circ} \mathrm{C}$. The black sticks refer to the powder pattern of $\mathrm{ReS}_{2}$ as reported by Wildervanck et al. ${ }^{46} \mathrm{~A}$ simulated powder pattern is also available in the ESI. $\dagger$ The amorphous background is from the glass substrate. 


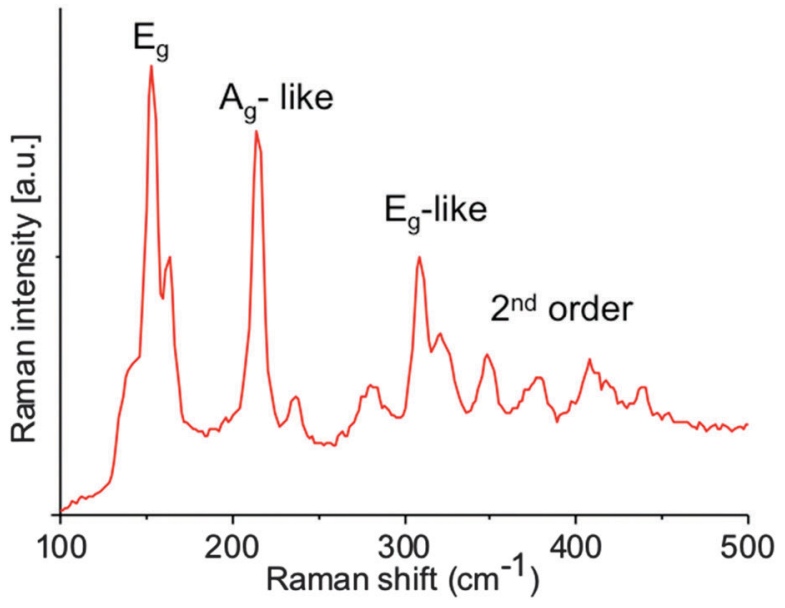

Fig. 3 The Raman spectrum of as-deposited $\mathrm{ReS}_{2}$ thin films produced by AA-CVD at $475{ }^{\circ} \mathrm{C}$. The profile is consistent with the Raman spectrum of $\mathrm{ReS}_{2}$ previously reported. ${ }^{28,29}$

which is consistent with the layered structure of $\mathrm{ReS}_{2}$. Selected area electron diffraction (SAED) patterns taken from these flakes show that they are highly crystalline (Fig. 4h).

Elemental analysis of the rhenium sulfide thin films by energy dispersive X-ray (EDX) spectroscopy. Thin films of $\mathrm{ReS}_{2}$ grown from $\operatorname{Re}\left(\mu-\mathrm{S}^{\mathrm{i}} \mathrm{Pr}\right)_{3}\left(\mathrm{~S}^{\mathrm{i}} \mathrm{Pr}\right)_{6}$ at $475{ }^{\circ} \mathrm{C}$ analysed as follows: Re $30 \%$, S 70\% giving a composition of $\operatorname{ReS}_{2.3}$. Molybdenum sulfide was also grown under the same conditions; SEM and EDX and Raman spectroscopies were consistent with that previously reported for this material $(\mathrm{ESI} \dagger){ }^{19}$
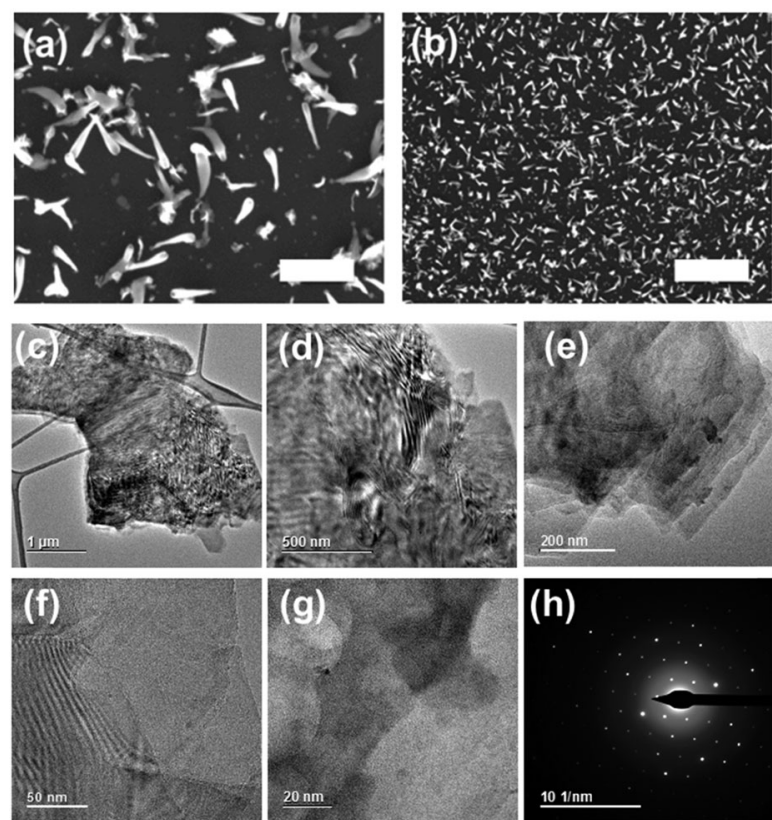

Fig. 4 Electron microscopy of rhenium disulfide $\left(\operatorname{ReS}_{2}\right)$ thin films. (a) and (b) Secondary electron SEM images $(10 \mathrm{kV})$ of thin films deposited by AACVD at $475{ }^{\circ} \mathrm{C}$. Scale bars represent: (a) $2 \mu \mathrm{m}$; (b) $5 \mu \mathrm{m}$. (c-g) Bright field TEM images of $\mathrm{ReS}_{2}$ thin films $(200 \mathrm{kV})$. (h) Selected area electron diffraction pattern of an $\mathrm{ReS}_{2}$ flake.

\section{Deposition and characterization of Mo-doped $\operatorname{ReS}_{2}$ thin films}

Rhenium-alloyed thin films of molybdenum disulfide $\left(\mathrm{Mo}_{1-x} \mathrm{Re}_{x} \mathrm{~S}_{2}\right.$ where $0 \leq x \leq 0.06$ ) were synthesised by AA-CVD at $475{ }^{\circ} \mathrm{C}$. EDX spectroscopy and ICP-OES confirmed that the rhenium dopant was successfully entrained into $\mathrm{MoS}_{2}$ thin films (Fig. 5). In all cases, the incorporation of Re into $\mathrm{MoS}_{2}$ is inefficient and the amount of Re found by EDX and ICP-OES in the films is only ca. $10 \%$ of that available Re in the aerosol feed.

The p-XRD patterns of $\mathrm{Mo}_{1-x} \mathrm{Re}_{x} \mathrm{~S}_{2}(0 \leq x \leq 0.06)$ for the ratios 1.79 and $1.80 \mathrm{~mol} \%$ show four reflections at $2 \theta=14.3$, $33.2,39.5$, and $58.7^{\circ}$ which can be assigned to the (002), (100), (103), and (110) reflections respectively. There was no significant change with the incorporation of 1.79 and $1.80 \mathrm{~mol} \%$ of $\mathrm{Re}$ on the pXRD patterns. However, on increasing the level of Re to more than $1.80 \mathrm{~mol} \%$, a change in the appearance of the diffraction patterns was observed; the (002) reflection became weak and broadened (Fig. 6). These changes in the powder pattern can be attributed to increasing Re mol\%, which affects the stacking layers of the S-Mo-S layers in the basal plane, ${ }^{47}$ which has previously been observed for Cr-doped $\operatorname{MoS}_{2} \cdot{ }^{21}$ Bright field TEM of the doped thin films (ESI $\dagger$ ) reveal that increasing the level of Re in the films does indeed cause a shift to material with a more amorphous appearance. This could potentially be caused the formation of intra-layer Re-Re bonds that locally disrupt the structure by $\mathrm{S}$ displacement (vide supra). The $d$-spacing for the (002) plane of the $\mathrm{MoS}_{2}$ film was $6.23 \AA$ which is larger than that reported by Schoenfeld et al. ${ }^{40}$ Indeed, in our and other reports of $\mathrm{MoS}_{2}$ synthesised by AACVD from dithiocarbamato molybdenum(Iv) precursors the observed spacings of 6.25 and $6.20 \AA{ }^{19,21}$ suggest that $\mathrm{MoS}_{2}$ produced by AA-CVD is lattice expanded in the [002] direction as compared to bulk material. The rhenium doped $\mathrm{MoS}_{2}$ displays a monotonic increase in the $d$-spacing that is linear with doping, suggesting that doping of Re affords a linear lattice expansion in the [002] direction of the crystal. If the literature value of $d(002)$ for bulk molybdenite is used, ${ }^{46}$ the trend becomes linear. We tentatively suggest that the effect of doping is pseudo-Vegardian.

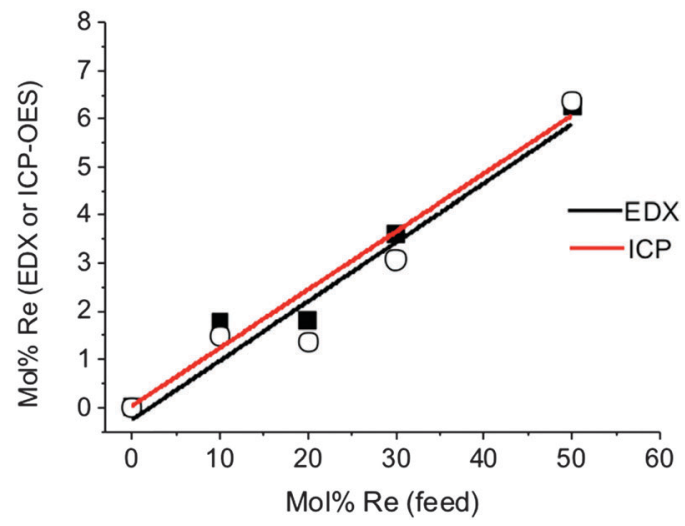

Fig. 5 Plot of mol\% Re found in elemental analysis of $\mathrm{Mo}_{1-x} \mathrm{Re}_{x} \mathrm{~S}_{2}(\mathrm{O} \leq$ $x \leq 0.06)$ thin films produced by AA-CVD at $475^{\circ} \mathrm{C}$ by EDX ( $\left.\mathbf{\square}\right)$ and ICP$\mathrm{OE}(\mathrm{O})$ spectroscopies as a function of varying mol\% of Re in the AA-CVD feed. 

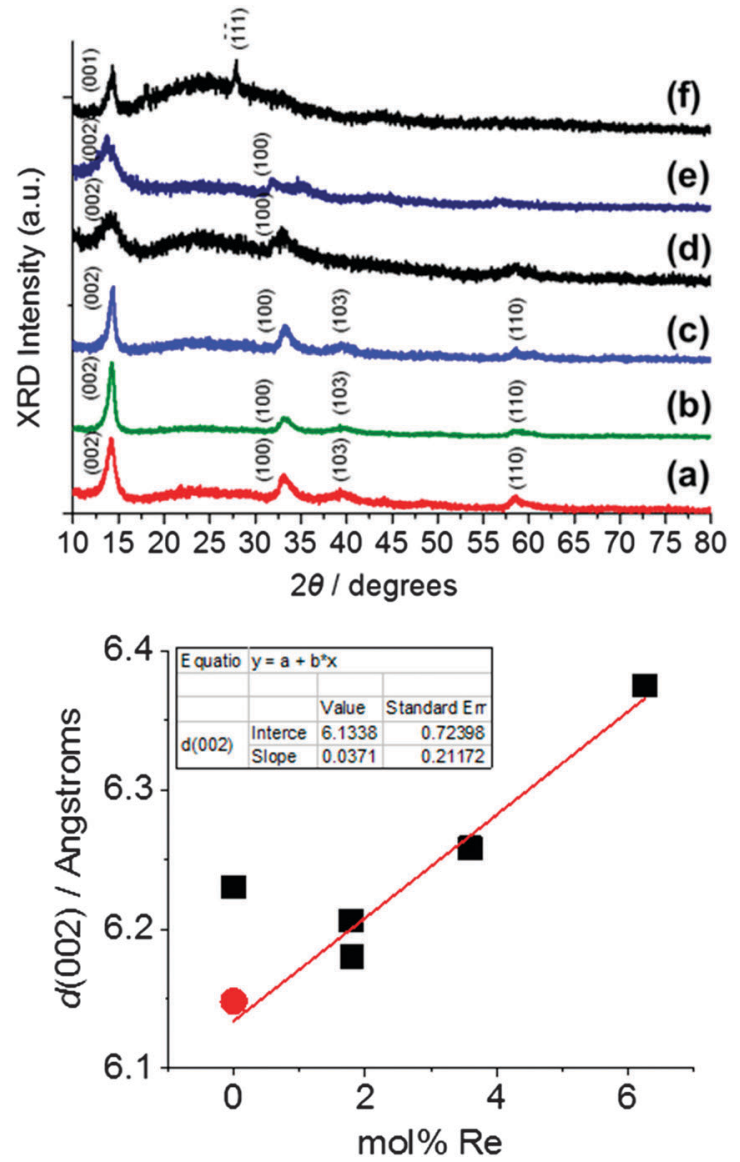

Fig. 6 Powder $\mathrm{X}$-ray diffraction patterns of $\mathrm{Mo}_{1-x} \mathrm{Re}_{x} \mathrm{~S}_{2}(0 \leq x \leq 0.06)$ films deposited by AA-CVD on glass substrates at $475{ }^{\circ} \mathrm{C}$. Top: Full pXRD patterns of (a) $0 \% \operatorname{Re}$, (b) $1.79 \mathrm{~mol} \% \mathrm{Re}$, (c) $1.80 \mathrm{~mol} \% \mathrm{Re}$, (d) $3.60 \mathrm{~mol} \% \mathrm{Re}$, (e) 6.25 mol\% Re., (f) $\operatorname{ReS}_{2}$ thin films. Powder patterns are offset for clarity bottom: the $d(002)$ spacing for Re-doped $\mathrm{MoS}_{2}$ measured by pXRD. (O) Literature interlayer distance value of crystalline $2 \mathrm{H}-\mathrm{MoS}_{2}$ (002) $6.15 \AA$ Schoenfeld et al. ${ }^{40}$ ( $)$ Measured $d$-spacing of $\mathrm{MoS}_{2}$ and Re-doped $\mathrm{MoS}_{2}$ from this study. Average value reported by this laboratory for $\mathrm{MoS}_{2}$ thin films deposited by AA-CVD is $6.23 \AA^{19,21}$ This observation suggests that $\mathrm{MoS}_{2}$ films produced by AA-CVD generally show lattice expansion in the [002] direction as compared to bulk molybdenite.

Raman spectroscopy was used to study $\mathrm{Mo}_{1-x} \mathrm{Re}_{x} \mathrm{~S}_{2}(0 \leq x \leq$ 0.06) films. The $\mathrm{MoS}_{2}$ film had two main bands observed at $407.6 \mathrm{~cm}^{-1}$ and $380.6 \mathrm{~cm}^{-1}$ corresponding to the $\mathrm{A}_{1 \mathrm{~g}}$ and $\mathrm{E}_{2 \mathrm{~g}}$ optical phonon modes (ESI $\dagger$ ). The Raman spectra for the Re-doped $\mathrm{MoS}_{2}$ films are shown in Fig. 7a. Significant changes in Raman spectra occurred at $3.6 \mathrm{~mol} \%$ Re with the appearance of a band which could correspond to the $\mathrm{A}_{1 \mathrm{~g}}$ mode for $\mathrm{ReS}_{2}$. Dependence of the Raman shift of the $\mathrm{E}_{2 \mathrm{~g}}^{1}$ and $\mathrm{A}_{1 \mathrm{~g}}$ optical modes of $\mathrm{Mo}_{1-x} \mathrm{Re}_{x} \mathrm{~S}_{2}$ on the amount of Re-dopant is shown in Fig. 7b. The difference in the magnitude of the shifts observed for both bands gives insight into the manner of doping. ${ }^{48}$ The $\mathrm{A}_{1 \mathrm{~g}}$ mode, which consists of the vibrational displacement of sulfur atoms only is only slightly shifted from $c a .407 \mathrm{~cm}^{-1}$ to $c a .406 \mathrm{~cm}^{-1}$. On the other hand, the $\mathrm{E}_{2 \mathrm{~g}}^{1}$ mode, which involves the vibration of metal and sulfur atoms in a layer is significantly shifted from $c a .382 \mathrm{~cm}^{-1}$ to ca. $376 \mathrm{~cm}^{-1}$. This is consistent with the substitutional doping of the heavier Re atoms into the Mo layer.
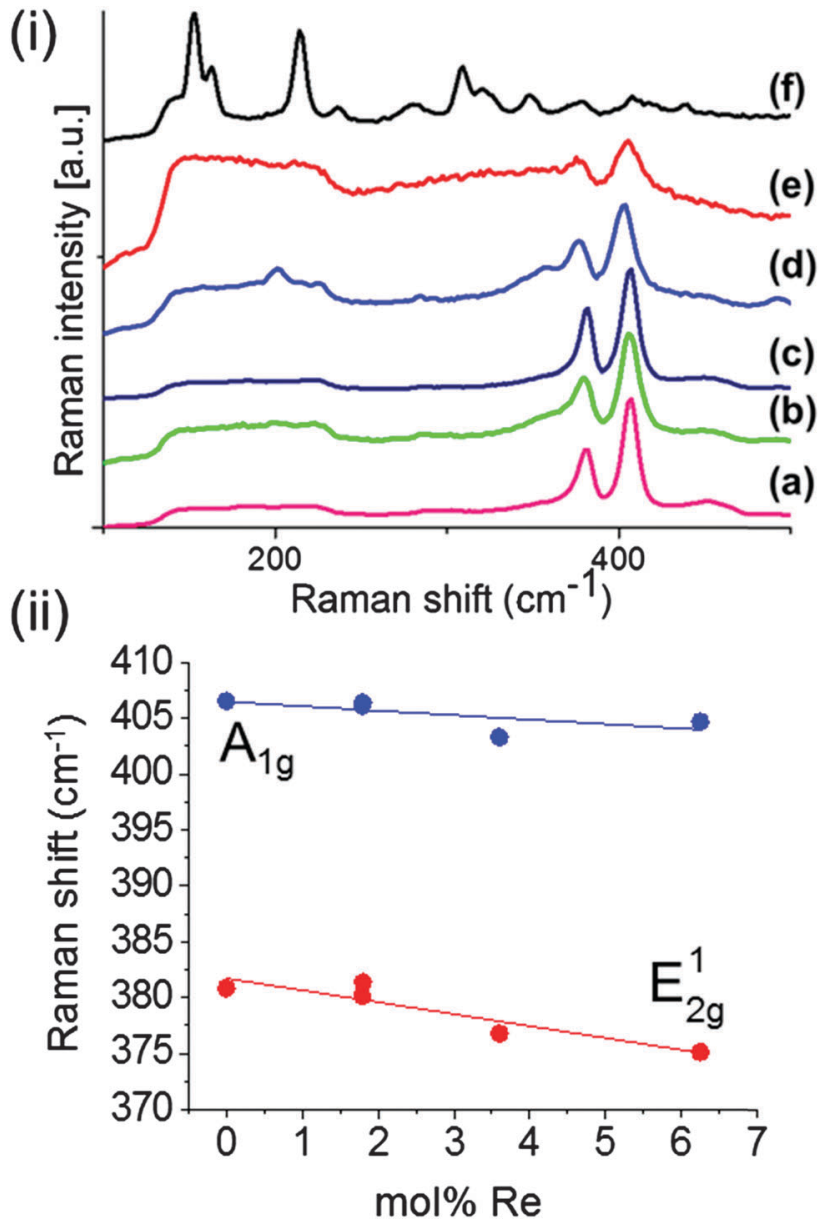

Fig. 7 (i) Raman spectra of $\mathrm{Mo}_{1-x} \mathrm{Re}_{x} \mathrm{~S}_{2}(0 \leq x \leq 0.06)$ thin films deposited at $475{ }^{\circ} \mathrm{C}$ by AA-CVD. (a) MoS2, (b) $1.79 \mathrm{~mol} \% \mathrm{Re}$, (c) $1.80 \mathrm{~mol} \% \mathrm{Re}$, (d) $3.60 \mathrm{~mol} \% \mathrm{Re}$, (e) $6.25 \mathrm{~mol} \% \mathrm{Re}$, (f) $\mathrm{ReS}_{2}$. Spectra are stacked for clarity. (ii) Dependence of the Raman shift of the $E_{2 g}^{1}$ and $A_{1 g}$ optical modes of $\mathrm{Mo}_{1-x} \mathrm{Re}_{x} \mathrm{~S}_{2}$ on the amount of Re-dopant.

The surface morphology of the $\mathrm{Mo}_{1-x} \mathrm{Re}_{x} \mathrm{~S}_{2}(0 \leq x \leq 0.06)$ films deposited by AA-CVD at $475{ }^{\circ} \mathrm{C}$ were investigated by SEM. Different morphologies were observed on changing the amount of rhenium; $\mathrm{MoS}_{2}$ had a lamellar morphology, but Re-doped $\mathrm{MoS}_{2} \mathbf{1 . 7 9 \%}$ gave clusters. Increasing the Re to $3.60 \%$ gave feather-like crystals which were also observed for material with $6.25 \%$ Re (Fig. 8). Representative elemental mapping of the Re-doped $\mathrm{MoS}_{2}$ thin film at $1.80 \%$ revealed that rhenium is evenly distributed in the film (Fig. 8). This was found in all alloyed films, suggesting that the isovalent substitution of Re(Iv) for Mo(Iv) was homogeneous under the conditions employed in this study.

\section{Conclusions}

Thin films of $\mathrm{Mo}_{1-x} \mathrm{Re}_{x} \mathrm{~S}_{2}(0 \leq x \leq 0.06)$ were deposited by AA-CVD from the single-source precursors $\operatorname{Re}\left(\mu-S^{i} \operatorname{Pr}\right)_{3}\left(S^{i} \operatorname{Pr}\right)_{6}(\mathbf{1})$ and $\mathrm{Mo}\left(\mathrm{S}_{2} \mathrm{CNEt}_{2}\right)_{4}$ (2). The Re-doped $\mathrm{MoS}_{2}$ thin films were deposited by using different molar ratios of (1) and (2). The morphology of thin films as investigated by SEM changes as the doping of $\mathrm{MoS}_{2}$ with rhenium is increased The p-XRD patterns 

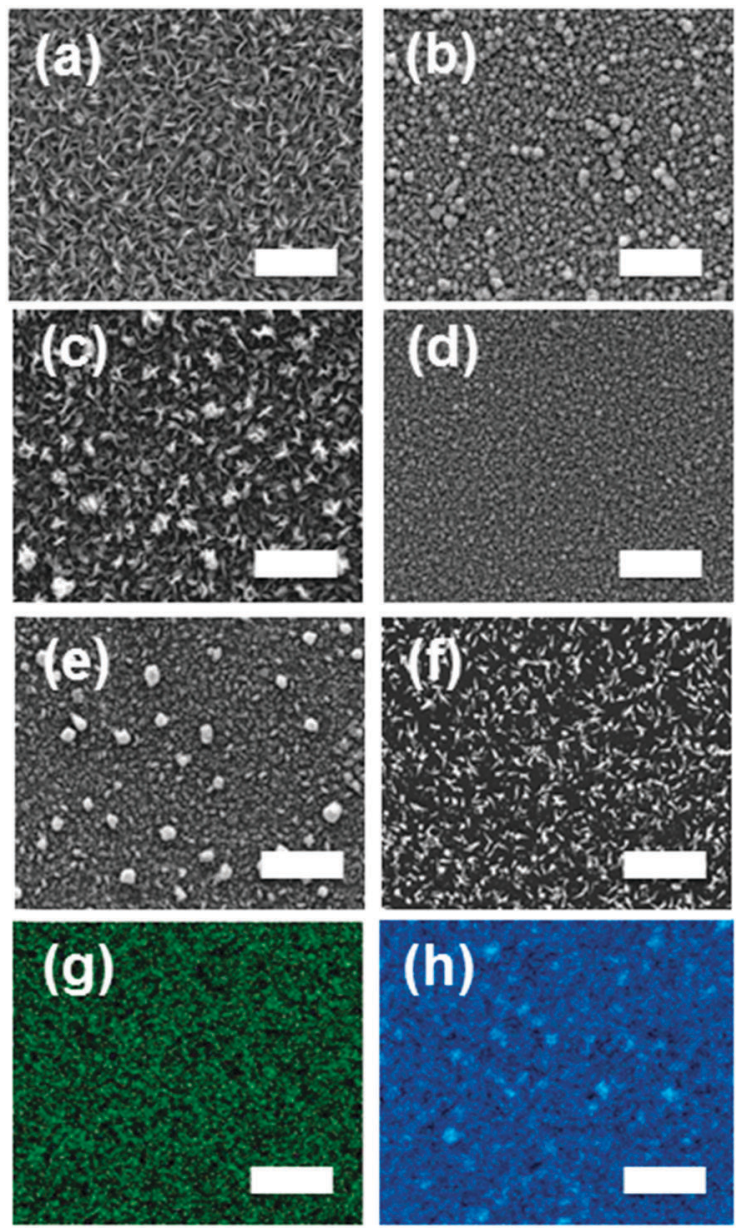

Fig. 8 Secondary electron SEM images (10 kV) of $\mathrm{Mo}_{1-x} \mathrm{Re}_{x} \mathrm{~S}_{2}(0 \leq x \leq 0.06)$ thin films deposited at $475{ }^{\circ} \mathrm{C}$ by AA-CVD. (a) 0 mol\% Re, (b) $1.79 \mathrm{~mol} \% \mathrm{Re}$, (c) $1.80 \mathrm{~mol} \% \mathrm{Re}$, (d) $3.60 \mathrm{~mol} \% \mathrm{Re}$, (e) $6.25 \mathrm{~mol} \% \mathrm{Re}$, and (f) ReS ${ }_{2}$; thin films were synthesized by using AA-CVD at $475^{\circ} \mathrm{C}$. EDX spectrum maps $(30 \mathrm{kV})$ of (g) Mo $L_{\alpha}$ and (h) Re $K_{\alpha}$ emission in 1.8 mol\% Re-doped $M_{0} S_{2}$ films. All scale bars represent $5 \mu \mathrm{m}$.

for the Re-doped $\mathrm{MoS}_{2}$ shows systematic variations in the peak shape, intensity, and the position of the (002) planes as the rhenium content varies. The $d(002)$ spacing in the alloys increases in a pseudo-Vegardian manner. EDX mapping of films demonstrated the spatial homogeneity of the doping. The $\mathrm{MoS}_{2}$ alloy with Re is a promising as a model system for the stability of ${ }^{99} \mathrm{Tc}$ in the host molybdenum disulfide crystal due to crystal radii and thermodynamic similarities between Re(Iv) and Tc(rv). The materials could also be exfoliated either by liquid or mechanical means to make novel 2D materials; we are currently investigating this possibility.

\section{Acknowledgements}

N. Al-D. thanks the Higher Committee for Education Development in Iraq (HCED) for funding and support, and also, the Chemistry Department and University of Sulaimani, Iraq, for allowing a period of study in the U.K. Some of the equipment used in this study were provided by the Engineering and Physical Sciences Research
Council U.K. (Core Capability in Chemistry, EPSRC grant number $\mathrm{EP} / \mathrm{K} 039547 / 1)$.

\section{Notes and references}

1 Q. H. Wang, K. Kalantar-Zadeh, A. Kis, J. N. Coleman and M. S. Strano, Nat. Nanotechnol., 2012, 7, 699-712.

2 M. Chhowalla, H. S. Shin, G. Eda, L.-J. Li, K. P. Loh and H. Zhang, Nat. Chem., 2013, 5, 263-275.

3 S. Z. Butler, S. M. Hollen, L. Cao, Y. Cui, J. A. Gupta, H. R. Gutiérrez, T. F. Heinz, S. S. Hong, J. Huang, A. F. Ismach, E. Johnston-Halperin, M. Kuno, V. V. Plashnitsa, R. D. Robinson, R. S. Ruoff, S. Salahuddin, J. Shan, L. Shi, M. G. Spencer, M. Terrones, W. Windl and J. E. Goldberger, ACS Nano, 2013, 7, 2898-2926.

4 B. Radisavljevic, A. Radenovic, J. Brivio, V. Giacometti and A. Kis, Nat. Nanotechnol., 2011, 6, 147-150.

5 D. Lembke and A. Kis, ACS Nano, 2012, 6, 10070-10075.

6 D. Jariwala, V. K. Sangwan, L. J. Lauhon, T. J. Marks and M. C. Hersam, ACS Nano, 2014, 8, 1102-1120.

7 H.-Y. Chang, S. Yang, J. Lee, L. Tao, W.-S. Hwang, D. Jena, N. Lu and D. Akinwande, ACS Nano, 2013, 7, 5446-5452.

8 B. W. H. Baugher, H. O. H. Churchill, Y. Yang and P. JarilloHerrero, Nano Lett., 2013, 13, 4212-4216.

9 A. Abderrahmane, P. J. Ko, T. V. Thu, S. Ishizawa, T. Takamura and A. Sandhu, Nanotechnology, 2014, 25, 365202.

10 M. Sun, J. Adjaye and A. E. Nelson, Appl. Catal., A, 2004, 263, 131-143.

11 W. M. R. Divigalpitiya, R. F. Frindt and S. R. Morrison, Science, 1989, 246, 369-371.

12 S. Ding, J. S. Chen and X. W. (David) Lou, Chem. - Eur. J., 2011, 17, 13142-13145.

13 M. Chhowalla and G. A. J. Amaratunga, Nature, 2000, 407, 164-167.

14 J. Chen, N. Kuriyama, H. Yuan, H. T. Takeshita and T. Sakai, J. Am. Chem. Soc., 2001, 123, 11813-11814.

15 K. F. Mak, C. Lee, J. Hone, J. Shan and T. F. Heinz, Phys. Rev. Lett., 2010, 105, 136805.

16 K. Chang, D. Geng, X. Li, J. Yang, Y. Tang, M. Cai, R. Li and X. Sun, Adv. Energy Mater., 2013, 3, 839-844.

17 S. Tongay, J. Zhou, C. Ataca, K. Lo, T. S. Matthews, J. Li, J. C. Grossman and J. Wu, Nano Lett., 2012, 12, 5576-5580.

18 W. Zhao, R. M. Ribeiro, M. Toh, A. Carvalho, C. Kloc, A. H. Castro Neto and G. Eda, Nano Lett., 2013, 13, 5627-5634.

19 A. Adeogun, M. Afzaal and P. O'Brien, Chem. Vap. Deposition, 2006, 12, 597-599.

20 V. A. Kuznetsov, A. S. Berdinsky, A. Y. Ledneva, S. B. Artemkina, M. S. Tarasenko and V. E. Fedorov, Sens. Actuators, A, 2015, 226, 5-10.

21 (a) D. J. Lewis, A. A. Tedstone, X. L. Zhong, E. A. Lewis, A. Rooney, N. Savjani, J. R. Brent, S. J. Haigh, M. G. Burke, C. A. Muryn, J. M. Raftery, C. Warrens, K. West, S. Gaemers and P. O'Brien, Chem. Mater., 2015, 27, 1367-1374; (b) A. A. Tedstone, D. J. Lewis, R. Hao, S.-M. Mao, P. Bellon, R. S. Averback, C. P. Warrens, K. R. West, P. Howard, S. Gaemers, 
S. J. Dillon and P. O’Brien, ACS Appl. Mater. Interfaces, 2015, 7, 20829-20834.

22 M. N. McCain, B. He, J. Sanati, Q. J. Wang and T. J. Marks, Chem. Mater., 2008, 20, 5438-5443.

23 S. Tongay, H. Sahin, C. Ko, A. Luce, W. Fan, K. Liu, J. Zhou, Y.-S. Huang, C.-H. Ho and J. Yan, et al., Nat. Commun., 2014, 5, 1-6.

24 D. Çakir, H. Sahin and F. M. Peeters, Phys. Chem. Chem. Phys., 2014, 16, 16771-16779.

25 S. Yang, S. Tongay, Q. Yue, Y. Li, B. Li and F. Lu, Sci. Rep., 2014, 4, 1-6.

26 K. Keyshar, Y. Gong, G. Ye, G. Brunetto, W. Zhou, D. P. Cole, K. Hackenberg, Y. He, L. Machado and M. Kabbani, et al., Adv. Mater., 2015, 27, 4640-4648.

27 W. Tu and B. Denizot, J. Colloid Interface Sci., 2007, 310, 167-170.

28 T. Fujita, Y. Ito, Y. Tan, H. Yamaguchi, D. Hojo, A. Hirata, D. Voiry, M. Chhowalla and M. Chen, Nanoscale, 2014, 6, 12458-12462.

29 K. Xu, H.-X. Deng, Z. Wang, Y. Huang, F. Wang, S.-S. Li, J.-W. Luo and J. He, Nanoscale, 2015, 7, 15757-15762.

30 H. Matzke and E. Vernaz, J. Nucl. Mater., 1993, 201, 295-309.

31 J. P. Icenhower, N. P. Qafoku, J. M. Zachara, D. M. Wellman and W. J. Martin, Waste Management Symposium WM2009/WM'09: HLW, TRU, LLW/ILW, Mixed, Hazardous Wastes and Environmental Management - Waste Management for the Nuclear Renaissance, United States, 2009.

32 B. T. Kenna and P. K. Kuroda, J. Inorg. Nucl. Chem., 1964, 26, 493-499.

33 K. Morris, F. R. Livens, J. M. Charnock, I. T. Burke, J. M. McBeth, J. D. C. Begg, C. Boothman and J. R. Lloyd, Appl. Geochem., 2008, 23, 603-617.
34 V. Neck and B. Kanellakopulos, Radiochim. Acta, 1987, 42, 135-138.

35 B. M. Dantas, A. L. A. Dantas, F. L. N. Marques, L. Bertelli and M. G. Stabin, Braz. Arch. Biol. Technol., 2005, 48, 215-220.

36 R. D. T. Shannon, Acta Crystallogr., Sect. A: Cryst. Phys., Diffr., Theor. Gen. Crystallogr., 1976, 32, 751-767.

37 G. E. Boyd and Q. V. Larson, J. Phys. Chem., 1956, 60, 707-715.

38 K. Xu, P. Hrma, W. Um and J. Heo, J. Nucl. Mater., 2013, 441, 262-266.

39 R. G. Dickinson and L. Pauling, J. Am. Chem. Soc., 1923, 45, 1466-1471.

40 B. Schoenfeld, J. J. Huang and S. C. Moss, Acta Crystallogr., Sect. B: Struct. Sci., 1983, 39, 404-407.

41 H. H. Murray, S. P. Kelty, R. R. Chianelli and C. S. Day, Inorg. Chem., 1994, 33, 4418-4420.

42 R. Lincoln and G. Wilkinson, Inorganic synthesis, 1980, vol. XX. 43 K. Mertis, P. G. Edwards, G. Wilkinson, K. M. A. Malik and M. B. Hursthouse, J. Chem. Soc., Dalton Trans., 1981, 705-716.

44 W.-W. Zhuang, D. M. Hoffman, D. Lappas and J. Cohen, Polyhedron, 1998, 17, 2583-2586.

45 T. Ouyang, K. P. Loh, H. Zhang, J. J. Vittal, M. Vetrichelvan, W. Chen, X. Gao and A. T. S. Wee, J. Phys. Chem. B, 2004, 108, 17537-17545.

46 J. C. Wildervanck and F. Jellinek, J. Less-Common Met., 1971, 24, 73-81.

47 L. Ye, S. Chen, W. Li, M. Pi, T. Wu and D. Zhang, J. Phys. Chem. C, 2015, 119, 9560-9567.

48 C. Lee, H. Yan, L. E. Brus, T. F. Heinz, J. Hone and S. Ryu, ACS Nano, 2010, 4, 2695-2700. 